\title{
An impossibility in sequencing problems
}

Citation for published version (APA):

Kayi, C., \& Ramaekers, E. (2008). An impossibility in sequencing problems. METEOR, Maastricht University School of Business and Economics. METEOR Research Memorandum No. 040 https://doi.org/10.26481/umamet.2008040

Document status and date:

Published: 01/01/2008

DOI:

10.26481/umamet.2008040

Document Version:

Publisher's PDF, also known as Version of record

\section{Please check the document version of this publication:}

- A submitted manuscript is the version of the article upon submission and before peer-review. There can be important differences between the submitted version and the official published version of record.

People interested in the research are advised to contact the author for the final version of the publication, or visit the DOI to the publisher's website.

- The final author version and the galley proof are versions of the publication after peer review.

- The final published version features the final layout of the paper including the volume, issue and page numbers.

Link to publication

\footnotetext{
General rights rights.

- You may freely distribute the URL identifying the publication in the public portal. please follow below link for the End User Agreement:

www.umlib.nl/taverne-license

Take down policy

If you believe that this document breaches copyright please contact us at:

repository@maastrichtuniversity.nl

providing details and we will investigate your claim.
}

Copyright and moral rights for the publications made accessible in the public portal are retained by the authors and/or other copyright owners and it is a condition of accessing publications that users recognise and abide by the legal requirements associated with these

- Users may download and print one copy of any publication from the public portal for the purpose of private study or research.

- You may not further distribute the material or use it for any profit-making activity or commercial gain

If the publication is distributed under the terms of Article $25 \mathrm{fa}$ of the Dutch Copyright Act, indicated by the "Taverne" license above, 
Çağatay Kayı, Eve Ramaekers

An Impossibility in Sequencing Problems

$\mathrm{RM} / 08 / 040$

JEL code: D63, C72

\section{METE@R}

Maastricht research school of Economics of TEchnology and ORganizations

Universiteit Maastricht

Faculty of Economics and Business Administration P.O. Box 616

NL - 6200 MD Maastricht

phone : ++31433883830

fax $\quad:++31433884873$ 


\title{
An Impossibility in Sequencing Problems*
}

\author{
Çağatay Kayı ${ }^{\dagger}$ and Eve Ramaekers ${ }^{\ddagger}$
}

\begin{abstract}
A set of agents with different waiting costs have to receive a service of different length of time from a single provider which can serve only one agent at a time. One needs to form a queue and set up monetary transfers to compensate the agents who have to wait. We prove that no rule satisfies efficiency of queues and coalitional strategy-proofness.
\end{abstract}

JEL Classification: D63, C72.

Keywords: Sequencing problems, Pareto-efficiency, coalitional strategy-proofness.

\section{Introduction}

A set of agents simultaneously arrive at a service facility that can only serve one agent at a time. Agents require service for different lengths of time. The waiting cost may vary from one agent to the other. Each agent is assigned a "consumption bundle" consisting of a position in the queue and a positive or negative transfer. Each agent has quasi-linear preferences over positions and transfers. For such a sequencing problem, a rule assigns each agent a position in the queue and a positive or negative transfer such that no two agents are assigned the same position, and the sum of the transfers is not positive.

Our objective is to identify rules that are well-behaved from the normative and strategic viewpoints. The first requirement is efficiency. It says that if an allocation is selected, there

${ }^{*}$ We thank Paulo Barelli, Walter Bossert, Bettina Klaus, François Maniquet, Manipushpak Mitra, Jay Sethuraman, William Thomson, Gábor Virág, and seminar participants at the University of Maastricht, Social Choice and Welfare Conference 2006, University of Rochester for their helpful discussions and suggestions.

${ }^{\dagger}$ Maastricht University, Department of Economics, 6200 MD Maastricht, The Netherlands. E-mail: C.Kayi@algec.unimaas.nl

${ }^{\ddagger}$ Center for Operations Research and Econometrics (CORE)Universit catholique de Louvain (UCL) Voie du Roman Pays, 34 B-1348 Louvain-la-Neuve Belgium E-mail: Eve.Ramaekers@uclouvain.be 
should be no other feasible allocation that each agent finds at least as desirable and at least one agent prefers. Since preferences are linear, Pareto-efficiency can be decomposed into two axioms: on the one hand, efficiency of queues, which says that a queue should minimize the total waiting cost, and on the other hand, balancedness, which says that transfers should sum up to zero. Second is a minimal fairness requirement, no-envy, which requires that no agent should prefer another agent's assignment to her own. No-envy implies efficiency of queues. Third is immunity to strategic behavior. As unit waiting costs may not be known, the rule should provide agents the incentive to reveal these costs truthfully. Strategy-proofness requires that each agent should find her assignment when she truthfully reveals her unit waiting cost at least as desirable as her assignment when she misrepresents it. ${ }^{1}$ We are also concerned about possible manipulations by groups, and consider coalitional strategyproofness: no group of agents should make each of its members at least as well off, and at least one of them better off, by jointly misrepresenting their waiting costs. Finally is nonbossiness: if an agent's change in her announcement does not affect her assignment, then it should not affect any other agent's assignment.

For sequencing problems, Pareto-efficiency and strategy-proofness are compatible (Suijs, 1996). For the subdomain of sequencing problems in which agents require service for the same length of time ${ }^{2}$, Pareto-efficiency, equal treatment of equals in welfare, and strategyproofness are compatible. (Kayı and Ramaekers, 2007). We show that if we impose the stronger incentive property of coalitional strategy-proofness with efficiency of queues, we have an impossibility result. Independently, Mutuswami and Mitra (2006) show that coalitional strategy-proofness, efficiency of queues and feasibility-which says that transfers should sum up less or equal to zero- are not compatible. In our proof, we make use of non-bossiness and get some corollaries: We show that no rule satisfies Pareto-efficiency and coalitional strategy-proofness, no rule satisfies Pareto-efficiency, non-bossiness, and strategy-proofness, and no rule satisfies no-envy, non-bossiness, and strategy-proofness.

In Section 2, we formally introduce the model. In Section 3, we define the properties on rules. In Section 4, we give the impossibility result.

\footnotetext{
${ }^{1}$ For an extensive survey on strategy-proofness, see Thomson, 2006.

${ }^{2}$ For queueing problems, see Mitra and Sen, 1998; Maniquet, 2003; Katta and Sethuraman, 2006; Chun 2006.
} 


\section{Model}

There is a finite set of agents $N$. Let $|N|=n \geq 2$. For each agent $i \in N$, let $r_{i} \in \mathbb{R}_{++}$be the servicing time and $c_{i} \in \mathbb{R}_{+}$be the unit waiting cost of $i \in N$. Let $r=\left(r_{i}\right)_{i \in N} \in \mathbb{R}_{++}^{N}$ and $c=\left(c_{i}\right)_{i \in N} \in \mathbb{R}_{+}^{N}$ be the lists of the servicing times and unit waiting costs respectively. A queue is a bijection $\sigma: N \rightarrow\{1,2, \ldots, n\}$. Let $\mathcal{Q}$ be the set of all queues. For each agent $i \in N$, we will denote $\sigma(i)$ as $\sigma_{i}$. Each agent $i \in N$ has to be assigned a position $\sigma_{i} \in\{1,2, \ldots, n\}$ in a queue $\sigma$ and may receive a positive or negative monetary transfer $t_{i} \in \mathbb{R}$. Preferences are linear over $X \equiv\{1,2, \ldots, n\} \times \mathbb{R}$. For each queue $\sigma \in \mathcal{Q}$ and each $i \in N$, let $P_{i}(\sigma)$ be the set of agents preceding agent $i$ in queue $\sigma$, i.e., $P_{i}(\sigma) \equiv\left\{j \in N \mid \sigma_{j}<\sigma_{i}\right\}$. If $i$ is served $\sigma_{i}$-th, her total waiting cost is $\sum_{l \in P_{i}(\sigma)} r_{l} c_{i}$. Her preferences can be represented by the function $u_{i}$ defined as follows: for each $\left(\sigma_{i}, t_{i}\right) \in X, u_{i}\left(\sigma_{i}, t_{i}\right)=-\sum_{l \in P_{i}(\sigma)} r_{l} c_{i}+t_{i}$. We use the following notational shortcut. If her waiting cost is $c_{i}^{\prime}$, then her preferences are represented by the function $u_{i}^{\prime}$, defined by $u_{i}^{\prime}\left(\sigma_{i}, t_{i}\right)=-\sum_{l \in P_{i}(\sigma)} r_{l} c_{i}^{\prime}+t_{i}$; if it is $\tilde{c}_{i}$, then we use $\tilde{u}_{i}\left(\sigma_{i}, t_{i}\right)=-\sum_{l \in P_{i}(\sigma)} r_{l} \tilde{c}_{i}+t_{i}$, and so on. A sequencing problem is defined as a list $s \equiv\left(r_{i}, c_{i}\right)_{i \in N} \in \mathbb{R}_{++}^{N} \times \mathbb{R}_{+}^{N}$. Let $\mathcal{S} \equiv \mathbb{R}_{++}^{N} \times \mathbb{R}_{+}^{N}$ be the class of all problems.

An allocation for $s \in \mathcal{S}$ is a pair $(\sigma, t) \equiv\left(\sigma_{i}, t_{i}\right)_{i \in N} \in X^{N}$. An allocation $(\sigma, t) \in X^{N}$ is feasible for $s \in \mathcal{S}$ if no two agents are assigned the same position in $\sigma$, (i.e., for each $\{i, j\} \subseteq N$ with $i \neq j$, we have $\sigma_{i} \neq \sigma_{j}$ ), and the sum of the coordinates of $t$ is non-positive, (i.e., $\left.\sum_{i \in N} t_{i} \leq 0\right)$. Let $Z(s)$ be the set of all feasible allocations for $s \in \mathcal{S}$. An (allocation) rule $\varphi$ is a function that associates with each problem $s \in \mathcal{S}$ a feasible allocation $\varphi(s) \in Z(s)$.

Given $s \in \mathcal{S}$ and $S \subseteq N, r_{S} \equiv\left(c_{l}\right)_{l \in S}$ and $c_{S} \equiv\left(c_{l}\right)_{l \in S}$ are restrictions of servicing times $r$ and unit waiting costs $c$ to $S$ respectively. Given $i \in N, r_{-i} \equiv\left(r_{l}\right)_{l \in N \backslash\{i\}}$ and $c_{-i} \equiv\left(c_{l}\right)_{l \in N \backslash\{i\}}$ are the restrictions of $r$ and $c$ to $N \backslash\{i\}$ respectively.

\section{Properties of rules}

In this section, we define properties of rules. Let $\varphi$ be a rule. First, if an allocation is selected, there should be no other feasible allocation that each agent finds at least as desirable and at least one agent prefers.

Pareto-efficiency: For each $s \in \mathcal{S}$ and each $(\sigma, t) \in \varphi(s)$, there is no $\left(\sigma^{\prime}, t^{\prime}\right) \in Z(s)$ such that for each $i \in N, u_{i}\left(\sigma_{i}^{\prime}, t_{i}^{\prime}\right) \geq u_{i}\left(\sigma_{i}, t_{i}\right)$ and for at least one $j \in N, u_{j}\left(\sigma_{j}^{\prime}, t_{j}^{\prime}\right)>u_{j}\left(\sigma_{j}, t_{j}\right)$. 
If an allocation is Pareto-efficient for $s$, any other allocation at which the queue is the same is also Pareto-efficient. Therefore, it is meaningful to speak of the efficiency of queues. It requires to minimize the total waiting cost. Thus, an allocation $(\sigma, t)$ is Pareto-efficient for $s$ if and only if for each $\sigma^{\prime} \in \mathcal{Q}$, we have $\sum_{i \in N} \sum_{l \in P_{i}\left(\sigma^{\prime}\right)} r_{l} c_{i} \geq \sum_{i \in N} \sum_{l \in P_{i}(\sigma)} r_{l} c_{i}$, i.e., $\sigma$ is efficient for $s$ and $\sum_{i \in N} t_{i}=0$, i.e., $t$ is balanced for $s$. Let $\mathcal{Q}^{*}(s)$ be the set of all efficient queues for $s$. For each $s \in \mathcal{S}$ and each $(\sigma, t) \in Z(s)$, we have $\sigma \in \mathcal{Q}^{*}(s)$ if and only if for each $\{i, j\} \subset N$ with $i \neq j$, if $\sigma_{i}<\sigma_{j}$, then $c_{i} / r_{i} \geq c_{j} / r_{j}$. (Smith, 1956) For simplicity, throughout the paper, we will assume that agents have unequal ratios of unit waiting costs and servicing time. Therefore, there is only one efficient queue.

Summarizing the discussion above, Pareto-efficiency can be decomposed into two axioms: Efficiency of queues: For each $s \in \mathcal{S}$ and each $(\sigma, t) \in \varphi(s)$, we have $\sigma \in Q^{*}(s)$.

Balancedness: For each $s \in \mathcal{S}$ and each $(\sigma, t) \in \varphi(s)$, we have $\sum_{i \in N} t_{i}=0$.

The next requirement is necessary for no agent to prefer another agent's assignment to her own.

No-envy: For each $s \in \mathcal{S}$, each $(\sigma, t) \in \varphi(s)$, and each $i \in N$, there is no $j \in N \backslash\{i\}$ such that $u_{i}\left(\sigma_{j}, t_{j}\right)>u_{i}\left(\sigma_{i}, t_{i}\right)$.

The last requirements are motivated by strategic considerations. The planner may not know the agents' cost parameters. If agents behave strategically when announcing them, neither efficiency nor equity may be attained. Thus, we require that each agent should find her assignment when she truthfully reveals her unit waiting cost at least as desirable as her assignment when she misrepresents it.

Strategy-proofness: For each $s \in \mathcal{S}$, each $i \in N$, and each $c_{i}^{\prime} \in \mathbb{R}_{+}$, if $(\sigma, t)=\varphi(s)$ and $\left(\sigma^{\prime}, t^{\prime}\right)=\varphi\left(r, c_{i}^{\prime}, c_{-i}\right)$, then $u_{i}\left(\sigma_{i}, t_{i}\right) \geq u_{i}\left(\sigma_{i}^{\prime}, t_{i}^{\prime}\right)$.

We also consider the requirement that no group of agents should be able to make each of its members at least as well off, and at least one of them better off, by jointly misrepresenting its members' waiting costs.

Coalitional strategy-proofness: For each $s \in \mathcal{S}$ and each $S \subseteq N$, there is no $c_{S}^{\prime} \in \mathbb{R}_{+}^{S}$ such that if $(\sigma, t)=\varphi(s)$ and $\left(\sigma^{\prime}, t^{\prime}\right)=\varphi\left(r, c_{S}^{\prime}, c_{N \backslash S}\right)$, then for each $i \in S$, we have $u_{i}\left(\sigma_{i}^{\prime}, t_{i}^{\prime}\right) \geq$ $u_{i}\left(\sigma_{i}, t_{i}\right)$ and for some $j \in S$, we have $u_{j}\left(\sigma_{j}^{\prime}, t_{j}^{\prime}\right)>u_{j}\left(\sigma_{j}, t_{j}\right)$.

The next requirement is that if an agent's change in her announcement does not affect her assignment, then it should not affect any other agent's assignment. 
Non-bossiness: For each $s \in \mathcal{S}$, each $i \in N$, and each $c_{i}^{\prime} \in \mathbb{R}_{+}$, if $\varphi_{i}(s)=\varphi_{i}\left(r, c_{i}^{\prime}, c_{-i}\right)$, then $\varphi(s)=\varphi\left(r, c_{i}^{\prime}, c_{-i}\right)$.

\section{Result}

First, we establish a relationship between efficiency of queues and coalitional strategyproofness, and non-bossiness.

Proposition 1. Let $\varphi$ be a rule satisfying efficiency of queues and coalitional strategyproofness, then it satisfies non-bossiness.

Proof. Let $\varphi$ be a rule satisfying the axioms of Proposition 1. We need to show that for each $s \in \mathcal{S}$, each $i \in N$, each $c_{i}^{\prime} \in \mathcal{R}_{+}$, if $z=\varphi(s)$ and $z^{\prime}=\varphi\left(r,\left(c_{i}^{\prime}, c_{-i}\right)\right)$ are such that $z_{i}=z_{i}^{\prime}$, then $z=z^{\prime}$. Indeed, let $s=(r, c) \in \mathcal{S}, i \in N, c_{i}^{\prime} \in \mathcal{R}_{+}, z=\varphi(s)$, and $z^{\prime}=\varphi\left(r,\left(c_{i}^{\prime}, c_{-i}\right)\right)$ be such that $z_{i}=z_{i}^{\prime}$. By contradiction, suppose that there is $j \in N$ such that $z_{j} \neq z_{j}^{\prime}$. Then, since $z_{i}=z_{i}^{\prime}$, we have $u_{i}\left(\sigma, t_{i}\right)=u_{i}\left(\sigma^{\prime}, t_{i}^{\prime}\right)$. By efficiency of queues, $\sigma_{j}=\sigma_{j}^{\prime}$. Since $z_{j} \neq z_{j}^{\prime}$, we have $t_{j} \neq t_{j}^{\prime}$. First, suppose $t_{j}>t_{j}^{\prime}$. Then, $u_{j}\left(\sigma, t_{j}\right)>u_{j}\left(\sigma^{\prime}, t_{j}^{\prime}\right)$ and there is $\left(c_{i}^{\prime}, c_{j}\right) \in \mathcal{R}_{+}^{\{i, j\}}$ such that $u_{i}\left(\sigma, t_{i}\right)=u_{i}\left(\sigma^{\prime}, t_{i}^{\prime}\right)$ and $u_{j}\left(\sigma, t_{j}\right)>u_{j}\left(\sigma^{\prime}, t_{j}^{\prime}\right)$, contradicting coalitional strategy-proofness. Second, suppose $t_{j}<t_{j}^{\prime}$. Then, $u_{j}\left(\sigma, t_{j}\right)<u_{j}\left(\sigma^{\prime}, t_{j}^{\prime}\right)$ and there is $\left(c_{i}, c_{j}\right) \in \mathcal{R}_{+}^{\{i, j\}}$ such that $u_{i}^{\prime}\left(\sigma, t_{i}\right)=u_{i}^{\prime}\left(\sigma^{\prime}, t_{i}^{\prime}\right)$ and $u_{j}\left(\sigma^{\prime}, t_{j}^{\prime}\right)>u_{j}\left(\sigma, t_{j}\right)$, contradicting coalitional strategy-proofness.

Then, we prove our main result.

Theorem 1. No rule satisfies efficiency of queues and coalitional strategy-proofness.

Proof. By contradiction, let $\varphi$ be a rule satisfying the axioms of Theorem 1 . Then, by Proposition 1, $\varphi$ satisfies non-bossiness. Now, assume that for each $i \in N$, we have $r_{i}=1$. We establish two claims:

Claim 1: For each $s \in \mathcal{S}$, each $i \in N$, and each $c_{i}^{\prime} \in \mathbb{R}_{+}$, if $(\sigma, t)=\varphi(r, c)$ and $\left(\sigma^{\prime}, t^{\prime}\right)=\varphi\left(r,\left(c_{i}^{\prime}, c_{-i}\right)\right)$ are such that $\sigma_{i}=\sigma_{i}^{\prime}$, then $(\sigma, t)=\left(\sigma^{\prime}, t^{\prime}\right)$. Let $s \in \mathcal{S}, i \in N, c_{i}^{\prime} \in \mathbb{R}_{+},(\sigma, t)=\varphi(r, c)$ and $\left(\sigma^{\prime}, t^{\prime}\right)=\varphi\left(r,\left(c_{i}^{\prime}, c_{-i}\right)\right)$ are such that $\sigma_{i}=\sigma_{i}^{\prime}$. By strategy-proofness, $-\sum_{l \in P_{i}(\sigma)} r_{l} c_{i}+t_{i} \geq-\sum_{l \in P_{i}\left(\sigma^{\prime}\right)} r_{l} c_{i}+t_{i}^{\prime}$ and $-\sum_{l \in P_{i}(\sigma)} r_{l} c_{i}^{\prime}+t_{i} \leq$ $-\sum_{l \in P_{i}\left(\sigma^{\prime}\right)} r_{l} c_{i}^{\prime}+t_{i}^{\prime}$. By assumption, for each $i \in N$, we have $r_{i}=1$. Thus, $-\left(\sigma_{i}-1\right) c_{i}+t_{i} \geq$ 
$-\left(\sigma_{i}^{\prime}-1\right) c_{i}+t_{i}^{\prime}$ and $-\left(\sigma_{i}-1\right) c_{i}^{\prime}+t_{i} \leq-\left(\sigma_{i}^{\prime}-1\right) c_{i}^{\prime}+t_{i}^{\prime}$. Thus, as $\sigma_{i}=\sigma_{i}^{\prime}$, we have $t_{i}=t_{i}^{\prime}$. By non-bossiness, $(\sigma, t)=\left(\sigma^{\prime}, t^{\prime}\right)$.

Claim 2: For each $s \in \mathcal{S}$ such that for each $j, k \in N$, we have $c_{j} \neq c_{k}$ if and only if $j \neq k$, for each $i \in N$, and each $c_{i}^{\prime} \in \mathbb{R}_{+}$such that for each $j \in N \backslash\{i\}$, we have $c_{i}^{\prime}>c_{j}$ if and only if $c_{i}>c_{j}$, if $(\sigma, t)=\varphi(s)$, then $(\sigma, t)=\varphi\left(r,\left(c_{i}^{\prime}, c_{-i}\right)\right)$.

Let $s \in \mathcal{S}, i \in N, c_{i}^{\prime} \in \mathbb{R}_{+}$be such that for each $j \in N \backslash\{i\}$, we have $c_{i}^{\prime} \neq c_{j}$ and $c_{i}^{\prime}>c_{j}$ if and only if $c_{i}>c_{j}$, and $\left.(\sigma, t)=\varphi(s),\left(\sigma^{\prime}, t^{\prime}\right)=\varphi\left(r, c_{i}^{\prime}, c_{-i}\right)\right)$. By efficiency of queues, $\sigma_{i}^{\prime}=\sigma_{i}$. Thus, by Claim $1,(\sigma, t)=\varphi\left(r,\left(c_{i}^{\prime}, c_{-i}\right)\right)$.

Claims 1 to 2 being proved, we now come to a contradiction. Without loss of generality, suppose $N=\{1,2, \ldots, n\}$. Let $\left\{c, c^{\prime}\right\} \subseteq \mathbb{R}_{+}^{N}$ be such that

(i) $c_{1}>c_{2}>c_{3} \ldots>c_{n}$

(ii) $c_{2}^{\prime}>c_{1}^{\prime}>c_{3}^{\prime}>\ldots>c_{n}^{\prime}$, and

(iii) for each $i \in N \backslash\{1\}, c_{i}^{\prime}=c_{i}$.

Let $(\sigma, t)=\varphi(s)$ and $\left(\sigma^{\prime}, t^{\prime}\right)=\varphi\left(r, c^{\prime}\right)$. By efficiency of queues, for each $i \in N$, we have $\sigma_{i}=i$, whereas $\sigma_{1}^{\prime}=2, \sigma_{2}^{\prime}=1$, and for each $i \in N \backslash\{1,2\}$, we have $\sigma_{i}=\sigma_{i}^{\prime}=i$. Thus, $(\sigma, t) \neq\left(\sigma^{\prime}, t^{\prime}\right)$. By strategy-proofness, $u_{1}\left(\sigma_{1}, t_{1}\right)=t_{1} \geq-c_{1}+t_{1}^{\prime}=u_{1}\left(\sigma_{1}^{\prime}, t_{1}^{\prime}\right)$ and $u_{1}^{\prime}\left(\sigma_{1}^{\prime}, t_{1}^{\prime}\right)=$ $-c_{1}^{\prime}+t_{1}^{\prime} \geq t_{1}=u_{1}^{\prime}\left(\sigma_{1}, t_{1}\right)$. That is, $t_{1}^{\prime} \in\left[t_{1}+c_{1}^{\prime}, t_{1}+c_{1}\right]$. Thus, agent 1 's transfer depends either on a constant, i.e., $\bar{t}_{1}=t_{1}+c$ with $c \in\left[c_{1}, c_{1}^{\prime}\right]$, or on its own announcement, i.e., $\bar{t}_{1}=t_{1}+f\left(c_{1}^{\prime}, c_{1}\right)$ with $f\left(c_{1}^{\prime}, c_{1}\right) \in\left[c_{1}, c_{1}^{\prime}\right]$. Clearly, this contradicts strategy-proofness.

The following paragraphs establish examples of rules that satisfy only one of the axioms in Theorem 1.

(i) Equally Distributed Pairwise Pivotal rule (Kayı and Ramaekers, 2007 and Suijs, 1996) satisfies efficiency of queues but not coalitional strategy-proofness.

(ii) Any rule that selects the same arbitrary queue and sets the transfer to each agent equal to zero satisfies coalitional strategy-proofness, but not efficiency of queues.

Finally, by using the implication of properties, we have the following corollaries.

\section{Corollary 1.}

1. No rule satisfies Pareto-efficiency and coalitional strategy-proofness.

2. No rule satisfies Pareto-efficiency, non-bossiness, and strategy-proofness. 
3. No rule satisfies no-envy, non-bossiness, and strategy-proofness. ${ }^{3}$

\section{References}

[1] Chun, Y. (2006) "No-envy in queueing problems," Economic Theory 29, 151-162.

[2] Katta, A. and J. Sethuraman (2006) "Cooperation in Queues," mimeo, Columbia University, New York, NY, USA.

[3] Kayı, C.. and E. Ramaekers (2007) "Characterizations of Pareto-efficient, fair, and strategy-proof allocation rules in queueing problems," mimeo, Center for Operations Research and Econometrics (CORE)Universit catholique de Louvain (UCL).

[4] Maniquet, F. (2003) "A characterization of the Shapley value in queueing problems," Journal of Economic Theory 109, 90-103.

[5] Mitra M. (2001) "Mechanism design in queueing problems," Economic Theory 17, 277305.

[6] Mitra M. and S. Mutuswami (2006) "Group Strategyproofness in Queueing Models," Economics Discussion Papers 610, University of Essex, Department of Economics.

[7] Mitra M., and A. Sen (1998) "Dominant strategy implementation of first best public decision," mimeo, Indian Statistical Institute, New Delhi, India.

[8] Suijs, J. (1996) "On incentive compatibility and budget balancedness in public decision making," Economic Design 2, 193-209.

[9] Thomson, W. (2006): "Strategy-proof resource allocation rules," mimeo, University of Rochester, Rochester, NY, USA.

[10] Smith, W. (1956) "Various optimizers for single stage production," Naval Research Logistics Quarterly, 3, 59-66.

\footnotetext{
${ }^{3} 1$. Since Pareto-efficiency implies efficiency of queues and by Theorem 1, we have the result. 2. Since the contradiction at the end of Theorem 1 is to strategy-proofness, the result follow from Proposition 1. 3. Assume that $\varphi$ satisfies no-envy. Let $c \in \mathcal{C},(\sigma, t)=\varphi(c),\{i, j\} \subset N$, with $i \neq j$ be such that $c_{i}>c_{j}$ but $\sigma_{i}>\sigma_{j}$. By no-envy, we have $u_{i}\left(\sigma_{i}, t_{i}\right) \geq u_{i}\left(\sigma_{j}, t_{j}\right)$ and $u_{j}\left(\sigma_{j}, t_{j}\right) \geq u_{j}\left(\sigma_{i}, t_{i}\right)$. Then, $\left(\sigma_{i}-\sigma_{j}\right) c_{i}+t_{j} \leq t_{i} \leq\left(\sigma_{i}-\sigma_{j}\right) c_{i}$ that contradicts $c_{i}>c_{j}$. It follows that no-envy implies efficiency of queues. The result follows from Theorem 1.
} 